\title{
Using Information Technology to Prepare Personnel to Implement Functional Behavioral Assessment and Positive Behavioral Support
}

\author{
Wayne Sailor, Rachel Freeman, Jody Britten, \\ Amy McCart, and Christopher Smith \\ Life Span Institute \\ University of Kansas \\ Terry Scott and Mike Nelson \\ Department of Special Education and Rehabilitation Counseling \\ University of Kentucky
}

\begin{abstract}
Reauthorization of the Individual With Disabilities Education Act (1997) produced new language concerned with placement and instruction of students who present challenging behaviors and for whom there is risk of disability determination. The result is an immediate need for preservice personnel preparation as well as staff and professional development practices and procedures concerned with functional behavioral assessment and positive behavioral support (PBS). Recent advances in information technologies are creating new opportunities for advancing this training agenda. This article examines some of the impediments to effective dissemination of training in PBS such as philosophical barriers, school discipline policies, and the inadequacy of present professional and staff training models. It suggests ways that new information technologies can overcome these obstacles and reviews some new approaches using CD-ROM and online instructional methodologies to advance the training agenda.
\end{abstract}

The explosion of new information technologies in the past decade has provided a much needed opportunity to reshape the landscape of both personnel training (preservice) and

Requests for reprints should be sent to Wayne Sailor, University Affiliated Program-Lawrence, University of Kansas, 1052 Dole Hall, Lawrence, KS 66045. Email: wsailor@ukans.edu. 
staff development (inservice) in virtually all human services professions and occupations. Historically, practicing teachers initially have had to depend on a knowledge base growing out of the ability of teacher educators to evaluate current research and translate the implications into practice. Once on the job, leaders have had to rely on their own resources and diligence to stay in touch with ongoing research. Lacking resources from university libraries with current journals, new books, and so on, it has been all too common for practicing teachers to fall prey to a well-known lag from research to teaching practice (Gersten, Vaughn, Deshler, \& Schiller, in press).

Staff development historically has presented similar challenges. The burden of imparting new research-based information on teaching practices to special education teachers in the field has been borne largely by state departments of education on limited funds provided through the Individuals With Disabilities Education Act (IDEA; 1997) for that purpose. The format for much state approved staff development traditionally has been what has come to be known as "the dog and pony show." Episodic conferences or workshops are held in either the district on a "teacher inservice" day or a central location in the state during the summer months. Experts are brought in to impart new information, group discussions are held, notebooks are issued, and the process is concluded.

There has long been a need for sustained, readily accessible contacts for new research-to-practice materials and information for teacher educators, practicing teachers, and state-level staff development personnel. Information technologies have responded to this need, and the result is a rapidly changing landscape for eliminating the lag from research to practice in special education and other professions. In this article, we focus on the opportunities for new options in teacher education and staff development arising from recent advances in information technology. Our case in point is the critical need to acquaint new, as well as practicing, teachers with the concept and methods of functional behavioral assessment (FBA) and the development of positive behavioral support plans (PBS).

\section{THE CHALLENGE POSED BY IDEA (1997)}

New language contained in the reauthorization of the Amendments to the Individuals With Disabilities Act (IDEA) of 1997, which was signed into law on June 4, 1997 has precipitated both crisis and opportunity by creating an immediate, national need for personnel preparation efforts in the areas traditionally concerned with placement and instruction of students who manifest behavioral problems associated with their disabilities or whose behavior places them at risk for disability determination (Turnbull \& Ruef, 1996).

The new concepts, to most educators, that have emerged in the statute and have pressing implications for the transfer of research-validated technology into practice (particularly for teachers, service providers in community settings, and families) are PBS and its key operative component, FBA. Section 614 (d)(3)(B)(i) of Pub. L. 105-17 states

In the case of a child whose behavior impedes his or her learning or that of others, the child's Individual Education Program (IEP) Planning team must consider, when appropriate, strategies, including positive behavioral intervention strategies and supports to address that behavior. (p. 71) 
In addition, Section 615(k)(1)(B)(i) of the law states that

If the local educational agency did not conduct a functional behavioral assessment and implement a behavioral intervention plan for such child before the behavior that resulted in the suspension described in subparagraph (A), the agency shall convene an IEP meeting to develop an assessment plan to address that behavior. (p. 83)

In addition, "if the child already has a behavioral intervention plan, the IEP team shall review the plan and modify it, as necessary, to address the behavior" [Section 615(k)(1)(B)(ii)]. The act also states that

In response to certain disciplinary actions by school personnel, the IEP team must, within ten days, meet to formulate a functional behavioral assessment plan to collect data for developing a behavior intervention plan, or if a behavior intervention plan already exists, the team must review and revise it (as necessary), to ensure that is addresses the behavior upon which disciplinary action is predicated. (p. 83)

This language is meant to address the issue of a student's potential removal from an educational setting or other change of placement due to suspension or expulsion for reasons of discipline.

A growing body of research demonstrates the effectiveness of PBS and provides specific techniques for reducing problem behavior that do not rely primarily on the use of consequences such as suspension and exclusion (Carr et al., 1999; Durand \& Carr, 1991; Kern, Childs, Dunlap, Clarke, \& Falke, 1994; Koegel, Koegel, \& Dunlap, 1996; Lalli, Browder, Mace, \& Brown, 1993; Lewis, Sugai, \& Colvin, 1998). Despite the effectiveness of such PBS strategies as FBA, information regarding how to apply research-validated practices in the classroom has not been made available to teachers and other professionals in a format that allows these strategies to become common practice (Anderson, Albin, Mesaros, \& Morelli-Robbins, 1993; Nelson, Roberts, Mathur, \& Rutherford, 1998; Ruef, Turnbull, Turnbull, \& Poston, 1999; Scott \& Nelson, 1999a). In fact, one of the most common requests for assistance from teachers is for help in working with students who engage in problem behavior (Horner, Diemer, \& Brazeau, 1992).

Traditional professional development models have struggled with a variety of challenges that impede effective dissemination of training in the effective implementation of PBS. Practitioner competencies, philosophical barriers, and school discipline policy issues are but a few of the challenges that impede the ability of schools and community agencies to deliver PBS and FBA information in a manner that is timely and more likely to promote the generalization of newly acquired professional skills. These issues are discussed in the following sections. We conclude by highlighting new formats and strategies for staff development that show promise for the dissemination of effective training in FBA.

\section{IMPEDIMENTS TO IMPLEMENTING FBA}

To be effective, schools must embrace the concept of FBA as a common routine whose procedures are adopted, supported, and equally shared across the school (Jolivette, Barton-Arwood, \& Scott, in press; Scott \& Nelson, 1999b). Yet, the issues that arise as 
impediments to school-wide implementation of effective FBA procedures in public schools are not purely training issues. As Scott and Nelson (1999a) suggested, the questions of implementation might rely not so much on what is trained and how it is delivered as to whether practitioners are willing to be trained and make changes. History provides us with enough evidence to predict that empirical support and legislation, without practitioner support, will be ineffective in effecting change. We first cover the issues related to practitioner characteristics and competencies, followed by a discussion of the practical barriers to school-wide implementation of effective FBA procedures.

\section{Practitioner Competencies}

When queried, teachers report challenging behaviors to be among the most difficult behaviors with which they deal on a daily basis, and they report feeling ill prepared to deal with these problems (Safran \& Safran, 1988; Scott, Nelson, \& Meers, 1999). Training practitioners to implement FBA is hindered by the fact that many persons lack even basic knowledge of strategies for dealing with problem behaviors. To them, the concept of FBA likely will be too abstract and advanced without exposure to some of the basic applied behavior analysis underpinnings and an understanding of why humans behave. Training in this depth of content is time consuming, complex, and often contrary to the philosophical beliefs of individuals (see next section). Few, if any, of the commercially available training programs in FBA provide a detailed primer in applied behavior analysis.

A second barrier at the personnel level involves individual competencies with collaboration and team decision making. Jolivette, Barton-Arwood, and Scott (in press) identified the following four individual dynamics that might act or interact to set the occasion for collaborative FBA team failure: Team members bring their own (a) unique perspectives of the student and presenting problems, (b) level of expertise with a given problem behavior, (c) agenda and level of commitment that might or might not match those of the group, and (d) working style, which might conflict with the working style of other members.

Again, understanding the process and making it work are two separate issues. It should be clear that simply training FBA as a collaborative process will be insufficient to guarantee effective systemic approaches with those who lack the skills necessary to engage in effective collaboration. If the FBA process is to be effective on a systemic level, training must take into account individual understanding and competencies in the areas of basic behavior modification, applied behavior analysis, and collaboration.

\section{Philosophical Barriers}

Because implementation of FBA as part of a school-wide process has implications for all persons in the school, the process can be defined as systemic in nature. Systems change is a dynamic process that involves both practical and philosophical factors (Garmston \& Wellman, 1999). As previously noted, effective training must focus not only on the core competencies needed by the personnel involved, but also on their existing belief systems and philosophical orientations. 
Because disagreements in this realm often amount to a politically charged debate, it is unlikely that addressing these concerns will change the minds of those truly invested in their philosophy. Rather, training should focus on providing procedural descriptions that incorporate a logically validated rationale, justifying procedures in advance of predictable objections. Clearly, it is unlikely that all persons within a given system will buy into any particular approach, and this will not be a realistic goal. As Sugai and Horner (1999) suggested, 80\% faculty consensus to participate seems to be sufficient to predict successful implementation of school-wide processes.

Although the FBA process has a history of use by professionals who work in the area of low-incidence disabilities and with students who exhibit serious behavior problems (e.g., Carr \& Durand, 1985; Day, Horner, \& O’Neill, 1994; Foster-Johnson \& Dunlap, 1993), the newness of this approach in public school programs and with typical and mild disability student populations relegates it to the position of "latest fad" in the minds of those who have seen procedures come and go in education. To avoid falling into this same trap, FBA must be justified rationally and trained using a set of prescriptive guidelines. However, FBA is not a static set of procedures that is used with every student. Rather, it is a dynamic process of inference and decision making, leading to individualized procedures that are based on the unique behaviors and contexts that surround individual students. Although the precise set of procedures likely will vary by individual student, the process must maintain a fidelity of implementation sufficient to maximize the probability of successful outcomes.

However, a recent national survey indicates that experts in the field of mild disabilities do not agree on the specific procedures that are necessary and sufficient to constitute best practice in conducting FBA with this population (Scott, Meers, \& Nelson, in press). Without consistent leadership, it seems ridiculous to assume that practitioners will be able to implement FBA with the fidelity necessary to produce systemwide meaningful outcomes. Under these conditions, it seems likely that FBA will follow other education fads into obscurity due to an inability to demonstrate efficiency and utility for schools. However, the questions that arise in FBA are empirical in nature and must be answered as a first priority. As Sugai, Horner, and Sprague (1999) so justifiably advocated, "it is imperative that researchers consolidate what is already known, translate their findings into applications for real-world contexts, and continue to extend the conceptual and applied knowledge base” (p. 256). If FBA is to be effectively trained and implemented on a school-wide basis, we must heed the admonition to continue to extend the research base to create the prescriptive guidelines necessary to facilitate reliable implementation.

\section{School Discipline Policies}

Discipline policies often are more political in nature than they are educational or therapeutic (Noguera, 1995). When a school, for example, takes a public stance of zero tolerance for a set of specific undesired behaviors, adopting policies and procedures that undermine or contradict such "get tough" policies is often political suicide. Once again, as we look at school-wide implementation, we must realize that no system will please 
everyone, regardless of its merits. The reality is that the use of physical security procedures and reactive exclusionary policies are associated with schools that are less safe and have an increased risk of problem behavior (Mayer \& Leone, 1999; Skiba \& Peterson, 2000). This issue is best approached via a campaign of public education to expel the myths and allow logic to attract a consensus of persons within the school to take the lead in facilitating meaningful change.

Most schools do engage in some instructional procedures designed to reduce the risk of challenging or dangerous behavior. Conflict resolution, restitution, character education, and a variety of other programs typically are implemented with a targeted student group or across the school with emphasis on a specific targeted group. Often, schools are quite invested in these programs and have data to justify their continued use. In some cases, schools might see FBA as a threat to what they have in place, looking at it as an "either-or" proposition. It must be stressed to schools that school-wide implementation of FBA does not preclude the use of any proactive or instructionally based interventions. Rather, FBA is a process that assists targeted programs and is implemented when students continue to have problems despite their involvement in these targeted programs.

However, it should be made clear up front that the FBA process will prescribe specific individualized intervention programs or strategies for these students who have failed. Existing school strategies will be a part of intervention for these students only when the FBA indicates that such strategies are a functional match for the identified needs of the student.

\section{INADEQUACIES OF TRADITIONAL PROFESSIONAL DEVELOPMENT MODELS}

As described earlier, traditional models of professional development are insufficient to address the need for ongoing professional growth, particularly for those trying to provide education and support to those children who manifest the most difficult behavioral problems. Many of the limitations are related to the organizational and resource challenges faced by schools and other provider agencies.

Agencies without large numbers of staff to be trained simply cannot generate enough "critical mass" for a state or regional PBS training team to justify committing large blocks of training days for on-site and follow-up support. These agencies often fall through the cracks unless they can combine with other small agencies to create the necessary mass. Some agencies, by virtue of geographical location (particularly in rural areas) have poor access to professional development resources.

Scheduling issues, especially with schools, wreak havoc when setting up professional development initiatives. Often, professional development specialists cannot negotiate effectively with districts or schools for release time that will enable teachers and other educational staff (administrators, teaching assistants, special education staff) to participate in instructional activities. Furthermore, there are added costs to acquire substitute teachers.

The sequencing of professional development to fit individual and organizational needs can be tough to agree on, including when to schedule days where several staff will be attending on-site instructional activities and how long these on-site activities will last. 
Conflicts inevitably occur, creating problems related to attendance. In addition, designing the contextual features of a professional development approach that will address the individual needs of staff members can be difficult to achieve. Finally, staff turnover issues can be problematic when longitudinal PBS training commitments are obtained. Some staff begin the training but never complete it, whereas newly hired staff frequently are introduced in the middle of a professional development project.

\section{Emerging Training Formats and Strategies}

New professional development strategies, emerging from information technology, offer the opportunity to address the unique organizational challenges schools and other agencies face directly. One method for disseminating PBS that might provide solutions to some of the problems described earlier is the introduction of online instructional resources. Web-based professional development approaches offer significant benefits above and beyond traditional professional development strategies. Online instruction can provide teachers with new ways of obtaining information using flexible, self-paced instructional opportunities. Online instructional methods are now available for professional development specialists to design systems allowing teachers to actively seek feedback, advice, and support. This type of approach can be valuable when it is difficult to set up an on-site visit and respond in a timely manner to a stressful situation a teacher or staff person might be encountering. Online instruction can reach a large audience and might be much more responsive to the needs of agencies by promoting access and dissemination of crucial resources regardless of geographic locales. Examples of online instructional materials currently available in the area of PBS include a pilot module, Understanding Problem Behavior, developed at the University of Kentucky (www.uky.edu/ rljone00/pbis/), and a full set of courses on PBS developed by the Online Academy (www.onlineacademy.org) at the University of Kansas.

Online and Web-based training. The University of Kansas Center for Research on Learning, in partnership with the Kansas University Affiliated Program, received funding from the Office of Special Education Programs in October 1997 to develop, over a 3-year period, a set of instructional modules formatted for delivery over the World Wide Web in an online, interactive instructional format. Designed to be a method of translating research into immediate practice for preservice teacher trainees, these modules are being developed to address three content areas: teaching reading to students with learning disabilities, using technology in the classroom, and implementing FBA and PBS. This project, called the Online Academy, is designed to rapidly deploy information regarding research-based strategies to facilitate best practice instructional methods; curricular adaptations; curriculum-based assessments; and school, family, and community partnerships. The foundations for the Online Academy modules are (a) identifying promising practices that have been validated through rigorous research methods, (b) creating modules that can be combined to form online courses, and (c) establishing a system of pedagogy that permits preservice and inservice training to proceed at an individualized pace. 
The vision held by the Online Academy consists of two parts. First, the Online Academy provides teachers with a flexible format for obtaining information about research-validated interventions. Second, the Online Academy is designed to provide opportunities for teachers to routinely access online instruction when they are in need of solutions for everyday problems in their classroom. The Online Academy modules were developed using a set of research standards with input from a jury of researchers, experienced instructors, and $1^{\text {st }}$-year teachers. These jurors were selected to assure that high-quality, research-validated interventions and strategies were designed so that the content of the modules would be appealing and useful for teachers. The Appendix presents the content map for the modular configuration of the PBS and FBA portion of the Online Academy. Taken as a whole, these modules capture the scope and "state of the art” of present research-validated practices in FBA and PBS.

In compiling the content of the modules, the PBS research team a the University of Kansas proceeded on the basis of the selection standards presented in Table 1.

Fortunately, much that has been published in the psychology and special education literature on FBA and PBS has been characterized by scientific rigor and conservative influences drawn with respect to the limitations of the database from each study. As in all areas of new knowledge, however, some published information is documented insufficiently or includes results from poorly executed research and therefore should not be advanced to practitioners absent from further replication and research. The standards presented in Table 1 allowed the Academy to construct modular content for teacher educators and staff development that met strict standards for the advancement of research findings into practice.

Each of the instructional modules identified in the content map for PBS presented in the Appendix is designed to convey information interactively through auditory, visual, and print-mediated formats that are roughly the equivalent of $1 \mathrm{hr}$ (or unit) in a preservice teacher education course. Thus, modules can be combined in groups of three to compose a college or university-level online, three-unit course for teacher education, or they can be configured individually for ongoing staff development with continuing educational units as an option.

Each module is composed of lessons that contain lists of readings, resources, audiostreamed information with graphics, specific practice exercises, self- or instructor assessments of skills acquired, and sources for more information. An additional module not shown in the Appendix is available for college and university professors in teacher

TABLE 1

Proposed Selection Standards

The research must have been conducted in instructional environments involving learners with disabilities.

The research must have been documented as being effective for learners with disabilities who are at risk for school failure.

The research must have been subjected to a documented external review process.

The research must have been disseminated or applied in a format that is designed for implementation by practitioners.

The research must be in an area of methodology or curriculum that generally is perceived as having a high priority need to improve practice.

The instructional resources used in the research must be available to the Online Academy. 
education or staff development coordinators and instructors. This "Instructors' module" is designed to prepare instructors to respond to users online and provide technical assistance to users entering the modules for the first time.

As can be seen from the Appendix, the total content of the PBS portion of the Online Academy is exhaustive of the present state-of-the-art in FBA. It is designed to acquaint the beginner, encountering these concepts and practices for the first time, with awareness-level information and the desire to move along and learn more. It advances with each successive module to more sophisticated levels of knowledge and practice, and it increases in scope from single behavioral problems to comprehensive lifestyle changes. It encompasses singular applications of FBA to individuals as well as extensions of FBA and PBS practices to become the basis for school-wide discipline applications. In short, the content of the PBS portion of the Online Academy is intended to be exhaustive of research to practice in FBA and PBS to the year 2001.

The instructional modules created by the Online Academy are available to disseminate conceptual information to teachers and other service providers as one component of a comprehensive staff development approach. The pedagogy of online instruction enables participants to acquire knowledge in an immediate manner, as opposed to more traditional inservice training such as attending site-based courses or consultant-based instruction. Online instruction has the capability of reaching large numbers of individuals, in geographically diverse areas of a state, providing a continual source of knowledge.

The Online Academy modules can be accessed by any computer with Internet capabilities and contain several options for use. For instance, the Online Academy modules include an option for audiostreamed material that requires a sound card and the G2 RealPlayer software program. However, access to the materials is available through print media as well. The Online Academy modules accommodate different learning styles while maintaining Bobby Compliance, for access by persons with sensory disabilities, and maintaining a strong value on achieving high standards for written content. Because of the diversity in settings that support students with problem behavior, the Online Academy modules have integrated examples of PBS strategies used in a variety of school and community settings and with students of all age ranges, types, and levels of disabilities. Efforts have been taken to increase generalization of PBS strategies to the variety of daily situations and settings that teachers and other support staff encounter.

Interactive $C D-R O M$ training. Recognizing the need for standardized, accountable, and accessible training by practitioners in procedures for conducting FBAs, faculty and staff at the University of Kentucky developed an interactive tutorial on FBA. Supported by a grant from the Kentucky Department of Education, a beta version was completed in the spring of 1999. Copies were distributed to all school districts within the state. It became apparent that the need for such a training package extended to the national level; therefore, a commercial version was developed and recently was published (Liaupsin, Scott, \& Nelson, 2000). This module includes an overview of the process, a systematic tutorial through the steps involved in conducting an FBA, and case studies that allow participants to perform these steps with actual students. Currently, work is proceeding on the development of a companion CD-ROM on developing behavior intervention plans based on FBA. 
CD-ROM training modules are advantageous in several respects. First, the CDROM drive is now a common component on the average computer, making this format extremely accessible to most school settings while maintaining portability. Second, the technology and cost required to produce CD-ROMs have come down to a level where they can be produced on a midlevel desktop computer (e.g., Macintosh G4). Individual CDs can be burned for about $\$ 1$, making it affordable to continue updating content and individualizing examples for specific school levels (i.e., elementary, middle, or high school). Third, video can be programmed directly onto a CD, allowing for learners to view and review specific examples at their convenience. Last, effective use of instructional technology within the training modules allows for very interactive and engaging training and application exercises.

\section{CONCLUSIONS AND RECOMMENDATIONS}

We believe that preservice training, ongoing technical assistance, and practical demonstrations of effect will be needed to assure successful implementation of the FBA process. These issues have immediate implications for teacher education and the manner in which we train schools to consider and use FBA. Assuming that teacher trainers will accept FBA, its underlying philosophy, and the systemic manner in which it is applied is far more than a simple training issue. Yet, evidence suggests that, even if accepted, the current "hit and run" model of training and inservice, which typically lacks necessary technical support to maintain practice, likely will be insufficient to change school-wide practice. Systems change will require a consensus of commitment by those for whom the system is composed. The course of negative and exclusionary policy (i.e., suspending or expelling students) is easily returned to because such practices provide immediate reinforcement to school personnel by eliminating an aversive stimulus (the "problem" student). If more proactive approaches are to be maintained, they must be implemented with sufficient fidelity to demonstrate consistent and pronounced positive effects.

The new amendments to IDEA (1997) reaffirm a commitment to educating students with disabilities in inclusive settings. Although inclusion in general education classrooms continues to be supported for a range of children and disability types, it continues to be problematic for students with challenging behavior. The emphasis on collaborative practices has opened the door for a team approach to intervention planning. Interactive teaming has been advocated to guide practices in school-wide discipline (Colvin, Kameenui, \& Sugai, 1993; Nelson, 1996), individual behavioral consultation (Lewis \& Sugai, 1996), and effective behavioral support (Sugai \& Horner, in press). However, these teaming strategies rely on collective brainstorming and input, as opposed to an individual "expert" model-introducing another change in the traditional system. Consequently, team-based intervention planning demands systemwide implementation, shared expertise, and adequate training in both intervention and collaboration skills.

Because FBA and subsequent functional behavioral interventions are best implemented by teams and established as processes across the school, training must involve all school staff members who will interact with students or have substantial opportunities to observe students in natural settings. FBA should not be seen as the role of the special education teacher, counselor, school psychologist, or other specialist. Rather, FBA must be conceived of and practiced as a schoolwide process. Although a 
teacher might ask for assistance in completing an FBA, the procedure itself should be seen as a normal part of the prereferral intervention process followed by all teachers. Because typically this is not the manner in which chronic challenging behaviors are handled, training requires schoolwide acceptance and commitment. This entails thinking about FBA as a proactive rather than reactive strategy. That is, FBA should not be thought of as being used solely for dangerous behaviors, or as a precursor to change in placement or school exclusion.

When used in a systemic and proactive manner (i.e., within a system of PBS), FBA should be used as a means of early intervention for students identified at risk for behavioral difficulties. When used in this proactive manner across the school, FBA can increase the likelihood of success across all students and decrease the need for more costly and less effective reactive (exclusionary) procedures.

Still, the 1997 amendments to IDEA mandate FBA as a reaction to extreme or chronic behavior problems. We believe that, although necessary in these instances, advocating the use of FBA only under these reactive conditions exemplifies a most inefficient use of the proactive technology. In an effort to maintain safe learning environments for all students while ensuring a free and appropriate public education for students with disabilities, the appropriate time to conduct an FBA is before the student has been suspended or moved to an alternative setting. Thus, training in PBS and FBA must be systemwide so that school staff might be aware of the rationale and skills necessary to implement effective screening and assessment procedures to prevent undesired behaviors.

Providing adequate training will require more than exposure to a single course or inservice workshop. Acquisition-level training should include peer coaching and teacher assistance team models and must provide practitioners with examples from their natural environment on which to work. As with any training, the more realistic training settings, the more likely it is that skills will generalize beyond training. Interactive training technologies, including online instruction, Web sites, CD-ROM modules, and online consultation are promising vehicles to allow practitioners to gain both concept acquisition and skill practice via an interactive format.

In summary, recent law requiring the use of FBA within a system of PBS presents several challenges to teacher education at both the preservice and inservice levels. Thus, we believe that the key to effective implementation of FBA will depend on our ability to create a comprehensive and interactive training package; justify our methods with logic, research, and real examples; encourage systemic implementation via collaborative teams; and facilitate successful outcomes via ongoing technical support.

Of course, whether the FBA process is ever used proactively in a reliable and effective school-wide manner will depend on whether this technology can be proven successful across all students. Our best shot at demonstrating this success likely will be with the same population of students that currently present the biggest challenge. We must implement FBA procedures proactively with students who demonstrate risk for violent and dangerous behaviors. Effective demonstrations with this challenging population will have the largest impact on practitioner opinion. However, if FBA is to be effective with these students, it must be proactive. Using FBA only under the letter of the law as a reaction to chronic problem behavior with these students will be unlikely to 
demonstrate the success needed to maintain its use on a more proactive and school-wide level.

We are confident FBA can and will be validated as an effective preventative approach to dealing with problem behaviors across the school. Our challenge is to train personnel to both accept and implement the technology with sufficient fidelity to ensure success. Further, we must continue efforts to produce and validate the most effective means by which these procedures can be understood, accepted, and implemented at the school level.

\section{ACKNOWLEDGMENTS}

This article was supported in part by U.S. Department of Education Grant No. H326S980003. The opinions expressed herein do not necessarily reflect the position or policy of the Department, and no official endorsement by the Department should be inferred.

\section{REFERENCES}

Anderson, J. L., Albin, R. W., Mesaros, R. A., Dunlap, G., \& Morelli-Robbins, M. (1993). Issues in providing training to achieve comprehensive behavioral support. In J. Reichle \& D. P. Wacker (Eds.), Communicative alternatives to challenging behavior (pp. 363-406). Baltimore: Brookes.

Carr, E. G., \& Durand, V. M. (1985). Reducing behavior problems through functional communication training. Journal of Applied Behavior Analysis, 18, 111-126.

Colvin, G., Kameenui, E., \& Sugai, G. (1993). Reconceptualizing behavior management and schooldiscipline in general education. Education and Treatment of Children, 16, 361-381.

Day, H. M., Horner, R. H., \& O’Neill, R. E. (1994). Multiple functions of problem behaviors: Assessment and intervention. Journal of Applied Behavior Analysis, 27, 279-289.

Durand, V.M., \& Carr, E. (1991). Functional communication training to reduce challenging behavior: Maintenance and application in new settings. Journal of Applied Behavior Analysis, 24, 251-264.

Foster-Johnson, L., \& Dunlap, G. (1993). Using functional assessment to develop effective, individualized interventions for challenging behaviors. Teaching Exceptional Children, 25, 44-50.

Garmston, R.J., \& Wellman, B.M. (1999). The adaptive school: A sourcebook for developing collaborative groups. Norwood, MA: Christopher-Gordon.

Horner, R.H., Diemer, S., \& Brazeau, K. (1992). Educational support for students with severe problem behaviors in Oregon: A descriptive analysis from the 1987-1988 school year. Journal of the Association for Persons with Severe Handicaps, 15, 125-132.

Individuals With Disabilities Education Act of 1975, Pub. L. 105-17, 20 U.S.C. § 1400 et seq. (Amended 1997).

Jolivette, K., Barton-Arwood, S., \& Scott, T.M. (in press). Functional behavioral assessment as a collaborative process among professionals. Education and Treatment of Children.

Kern, L., Childs, K.E., Dunlap, G., Clarke, S., \& Falk, G.D. (1994). Using assessment-based curricular intervention to improve the classroom behavior of a student with emotional an behavioral challenges. Journal of Applied Behavior Analysis, 27, 7-19.

Koegel, L.K., Koegel, R.L., \& Dunlap, G. (1996). Positive behavioral support: Including people with difficult behavior in the community. Baltimore: Brookes.

Lalli, J.S., Browder, D.M., Mace, F.C., \& Brown, D.K. (1993). Teacher use of descriptive analysis data to implement interventions to decrease students' problem behaviors. Journal of Applied Behavior Analysis, 26, 227-238.

Lewis, T., \& Sugai, G. (1996). Descriptive and experimental analysis of teacher and peer attention and the use of assessment-based intervention to improve the pro-social behavior of a student in a general education setting. Journal of Behavioral Education, 6, 6-24. 
Lewis, T.J., Sugai, G., \& Colvin, G. (1998). Reducing problem behavior through a school-wide system of effective behavioral support: Investigation of a school-wide social skills training program and contextual interventions. School Psychology Review, 27, 446-459.

Liaupsin, C.J., Scott, T.M., \& Nelson, C.M. (2000). Functional behavioral assessment: An interactive tutorial. Longmont, CO: Sopris West.

Mayer, M.J., \& Leone, P.E. (1999). A structural analysis of school violence and disruption: Implications for creating safer schools. Education and treatment of Children, 22, 333-358.

Nelson, J.R. (1996). Designing schools to meet the needs of students who exhibit disruptive behavior. Journal of Emotional and Behavioral Disorders, 4(3), 147-161.

Nelson, J.R., Roberts, M., Mathur, S., \& Rutherford, R.B. (1998). Has public policy exceeded our knowledge base? A review of the functional behavioral assessment literature. Behavior Disorders, 24, 169-179.

Noguera, P.A. (1995). Preventing and producing violence: A critical analysis of responses to school violence. Harvard Educational Review, 65, 189-212.

Ruef, M.B., Turnbull, A.P., Turnbull, H.R., \& Poston, D. (1999). Perspectives of five stakeholder groups: challenging behavior of individuals with mental retardation and/or autism. Journal of Positive Behavior Interventions, 1, 43-58.

Safran, S.P., \& Safran, J.S. (1988). Perceptions of problem behaviors: A review and analysis of research. In R.B. Rutherford , C.M. Nelson, \& S.R. Forness (Eds.), Bases of severe behavioral disorders in children and youth (pp. 132-138). Boston: College-Hill.

Scott, T.M., Meers, D.T., \& Nelson, C.M. (in press). Toward a consensus of functional behavioral assessment for students with mild disabilities in public school contexts: A national survey. Education and Treatment of Children.

Scott, T.M., \& Nelson, C.M. (1999a). Functional behavioral assessment: Implications for training and staff development. Behavioral Disorders, 24, 249-252.

Scott T.M., \& Nelson, C.M. (1999b). Using functional assessment to develop effective intervention plans: A practical classroom application. Journal of Positive Behavioral Support, 1, 242-251.

Scott, T.M., Nelson, C.M., \& Meers, D.T. (1999). [A survey of emergency and probationary teachers' perceptions of the match between problems in the classroom and their teacher preparation program]. Unpublished raw data.

Skiba, R.J., \& Peterson, R.L. (2000). School discipline at a crossroads: From zero tolerance to early response. Exceptional Children, 66, 335-347.

Sugai, G., \& Horner, R.H. (1999). Discipline and behavioral support: Practices, pitfalls and promises. Effective School Practices, 17, 10-22.

Sugai, G., \& Horner, R.H. (in press). Discipline and behavioral support: Preferred processes and practices. Effective School Practices.

Sugai, G., Horner, R.H., \& Sprague, J.R. (1999). Functional-assessment-based behavior support planning: Research to practice to research. Behavioral Disorders, 24, 253-257.

Turnbull, A.P., \& Ruef, M. (1996). Family perspectives on problem behavior. Mental Retardation, 34, 280293. 